\title{
Definitions for Loss of Domain: An International Delphi Consensus of Expert Surgeons
}

\author{
Samuel G. Parker ${ }^{1} \cdot$ Steve Halligan $^{2}$ - Mike K. Liang ${ }^{3}$. Filip E. Muysoms ${ }^{4}$. \\ Gina L. Adrales ${ }^{5} \cdot$ Adam Boutall $^{6} \cdot$ Andrew C. de Beaux $^{7} \cdot$ Ulrich A. Dietz $^{8}$. \\ Celia M. Divino ${ }^{9} \cdot$ Mary T. Hawn $^{10} \cdot$ Todd B. Heniford $^{11} \cdot$ Joon P. Hong $^{12}$.

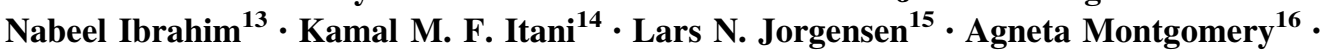 \\ Salvador Morales-Conde ${ }^{17}$ • Yohann Renard ${ }^{18}$ • David L. Sanders ${ }^{19} \cdot$ Neil J. Smart $^{20}$ • \\ Jared J. Torkington $^{21}$ - Alastair C. J. Windsor ${ }^{1}$
}

Published online: 17 December 2019

(C) The Author(s) 2019

\begin{abstract}
Background No standardized written or volumetric definition exists for 'loss of domain' (LOD). This limits the utility of LOD as a morphological descriptor and as a predictor of peri- and postoperative outcomes. Consequently, our aim was to establish definitions for LOD via consensus of expert abdominal wall surgeons.

Methods A Delphi study involving 20 internationally recognized abdominal wall reconstruction (AWR) surgeons was performed. Four written and two volumetric definitions of LOD were identified via systematic review. Panelists completed a questionnaire that suggested these definitions as standardized definitions of LOD. Consensus on a preferred term was pre-defined as achieved when selected by $\geq 80 \%$ of panelists. Terms scoring $<20 \%$ were removed.

Results Voting commenced August 2018 and was completed in January 2019. Written definition: During Round 1, two definitions were removed and seven new definitions were suggested, leaving nine definitions for consideration. For Round 2, panelists were asked to select all appealing definitions. Thereafter, common concepts were identified during analysis, from which the facilitators advanced a new written definition. This received $100 \%$ agreement in Round 3. Volumetric definition: Initially, panelists were evenly split, but consensus for the Sabbagh method was achieved. Panelists could not reach consensus regarding a threshold LOD value that would preclude surgery. Conclusions Consensus for written and volumetric definitions of LOD was achieved from 20 internationally recognized AWR surgeons. Adoption of these definitions will help standardize the use of LOD for both clinical and academic activities.
\end{abstract}

Electronic supplementary material The online version of this article (https://doi.org/10.1007/s00268-019-05317-z) contains supplementary material, which is available to authorized users.

Samuel G. Parker

samgparker@nhs.net

1 The Abdominal Wall Unit, University College London Hospital, 235 Euston Road, London NW1 2BU, UK

2 UCL Centre for Medical Imaging, 2nd floor Charles Bell House, 43-45 Foley Street, London W1W 7TS, UK

3 Department of Surgery, McGovern Medical Center, University of Texas Health Science Center, 5656 Kelley Street, Houston, TX 77026, USA
Department of Surgery, Maria Middelares Hospital, Buitenring-Sint-Denijs 30, 9000 Ghent, Belgium

5 Division of Minimally Invasive Surgery, The John Hopkins Hospital, 600 North Wolfe Street Blalock 618, Baltimore, MD 21287, USA

6 The Colorectal Unit, Groote Schuur Hospital, Main Road, Observatory, Cape Town 7925, South Africa

7 Department of Surgery, Royal Infirmary of Edinburgh, Edinburgh EH16 4SA, UK 


\section{Introduction}

The number of ventral hernia repairs performed each year worldwide is increasing $[1,2]$. This is due to an aging population [3], an increasing prevalence of obesity [4] and an increasing number of intra-abdominal surgical procedures [2]. The proportion of complex ventral hernias (CVHs) is also increasing, not only due in part to the reasons mentioned already but also because of improved intensive care [5]. For patients who have had previous intra-abdominal sepsis and laparostomies, the ventral defect is often left open and closed later using negative pressure dressings (fascial traction) or skin grafts. Ultimately, this predisposes to either fascial dehiscence or an anterior abdominal wall covered solely with skin; large ventral hernias then ensue. In such patients, a significant proportion of the abdominal viscera reside in a hernia beyond the abdomino-pelvic compartment, and their repair presents a significant surgical challenge. Patients with large $\mathrm{CVH}$ are often described as having 'loss of domain' (LOD) or 'loss of abdominal domain' [6]. The term refers to the loss of abdomino-pelvic compartment volume and the necessity for abdominal viscera to reside within the hernia sac.

Despite being used commonly, LOD lacks a single, standardized written and volumetric definition. A recent systematic review explored definitions of LOD and found four written definitions and two volumetric definitions in the indexed surgical literature [7]. For LOD to be a useful concept, a standardized definition that is applied consistently is needed. For example, ventral hernias with

8 Department of Visceral, Vascular and Thoracic Surgery, Kantonal Hospital of Olten, Baselstrasse 150, Olten 4600, Switzerland

9 Department of General Surgery, Department of Surgery, Mount Sinai School of Medicine, New York, NY 10029, USA

10 Department of Surgery, Stanford University Medical Center, 300 Pasteur Drive, Palo Alto, CA 94304, USA

11 Division of Gastrointestinal and Minimally Invasive Surgery, Department of Surgery, Carolinas Medical Center, 1000 Blythe Boulevard, Charlotte, NC 28203, USA

12 Department of Plastic Surgery, Asan Medical Center, University of Ulsan, 88 Oympicro, 43gil Songpagu, Seoul 05505, South Korea

13 Department of General Surgery, Macquarie University Hospital, 3 Technology Pl, Macquarie University, Sydney, NSW 2109, Australia

14 Department of General Surgery, Veterans Affairs Boston Health Care System, Boston and Harvard Universities, 1400 VFW Parkway, West Roxbury, MA 02132, USA

15 Digestive Disease Center, Bispebjerg University Hospital, Bispebjerg Bakke 23, 2400 Copenhagen, NV, Denmark significant LOD have been reported to frequently recur after repair [8], but as no standardized volumetric description exists, the true prognostic value of LOD has not been properly investigated. In order to rectify this, we used the Delphi method to survey an international panel of recognized academic hernia surgeons, so as to reach consensus regarding standardized written and volumetric definitions of LOD.

\section{Method and design}

We used the Delphi method [9] to establish consensus. The Delphi method is a consensus-based technique that stipulates a systematic framework to collect and aggregate informed judgements from a group of participants over multiple iterations [10]. We used five phases: questionnaire development (phase 1), expert panel selection (phase 2), followed by three rounds of questionnaire distribution, data acquisition and analysis, and iteration (phases 3, 4 and 5). Controlled feedback from sequential rounds encourages panelists to reassess, deliberate and either confirm or alter their responses. The Delphi method has been used extensively for healthcare research [11-13].

\section{Questionnaire development}

To administer the questionnaire, a PowerPoint presentation (Microsoft PowerPoint for Mac 2016, version 16.0, Microsoft Corporation, Washington, USA) of eight slides

16 Department of Surgery, Skane University Hospital Malmo, 20205 Malmo, Sweden

17 Unit of Innovation in Minimally Invasive Surgery, Department of General and Digestive Surgery, University Hospital "Virgen del Rocio", Betis-65, 1, 41010 Seville, Spain

18 Department of General, Digestive and Endocrine Surgery, Robert-Debre' University Hospital, University of Reims Champagne-Ardenne, Rue Cognacq-Jay, 51092 Reims Cedex, France

19 Department of General and Upper GI Surgery, North Devon, District Hospital, Raleigh Park, Barnstaple, Devon EX31 4JB, UK

20 Exeter Surgical Health Services Research Unit (HeSRU), Royal Devon and Exeter Hospital, Barrack Road, Exeter, Devon EX2 5DW, England, UK

21 Department of Colorectal Surgery, University Hospital of Wales, Cardiff CF14 4XW, UK 
(a)

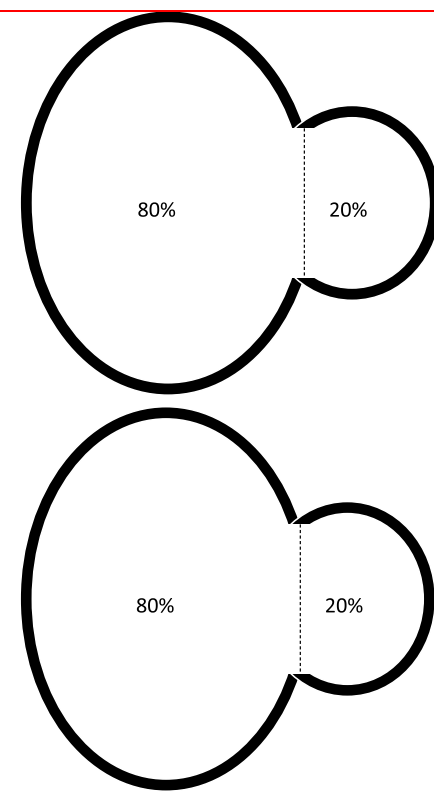

Sabbagh method (highlight if preferred):

Loss of domain $=20 \%$

LOD is calculated as a \% of the 'total peritoneal volume' (TPV).

$\mathrm{LOD}=\mathrm{HSV} / \mathrm{ACV}+\mathrm{HSV}$ or LOD $=\mathrm{HSV} / \mathrm{TPV}$

Tanaka method (highlight if preferred):

Loss of domain $=0.25$

i.e. $=20 / 80=0.25$

LOD is a ratio of the 'hernia sac volume' (HSV) to 'Abdominal

cavity volume' (ACV). LOD = HSV/ACV.

(b)

$$
\begin{gathered}
\text { 1.Tanaka method } \\
\text { Loss of domain }=0.25 \\
\text { i.e. }=20 / 80=0.25
\end{gathered}
$$

LOD is a ratio of the 'hernia sac volume' (HSV) to 'Abdominal cavity volume' (ACV). LOD = HSV/ACV.

\section{Sabbagh method \\ Loss of domain $=20 \%$}

LOD is calculated as a \% of the 'total peritoneal volume' (TPV). LOD = Hernia sac volume (HSV)/ Abdominal cavity volume $(\mathrm{ACV})+\mathrm{HSV}$ or LOD $=\mathrm{HSV} / \mathrm{TPV}$.

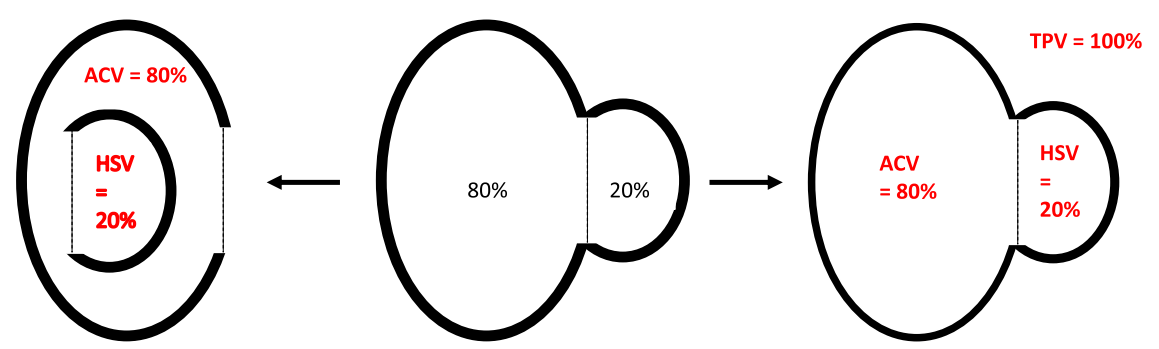

Fig. 1 a Two schematic diagrams used in Round 1 to illustrate the Tanaka and Sabbagh methods for describing loss of domain. b Schematic diagram to facilitate understanding and accurately describe the Tanaka and Sabbagh volumetric definitions. (Diagram used for Rounds 2 and 3 )

was constructed (Online supplement 1) and distributed to panelists.

Slide 1: Explained the Delphi method and voting process.

Slides 2, 3: The existing written definitions of LOD were listed in alphabetical order to eliminate bias. Panelists were asked to select their preferred definition.

Slide 4: $\quad$ A free-text slide followed allowing panelists to insert additional definitions and/or to make comments.

Slides 5, 6: To establish a volumetric definition. The lead researchers designed two different schematic diagrams depicting the abdominal and hernia sac cavities. Panelists were asked to select their preferred definition (Fig. 1a).

Slide 7: $\quad$ A free-text slide for additional comments regarding volumetric definitions.

Slide 8: The panelists were asked to vote on a threshold value for LOD, above which they believed the risk of postoperative complications becomes clinically significant, and therefore the value above which they might consider not operating at all. 
Table 1 Results of voting Rounds 1-3 of the Delphi process for consensus on written and volumetric definitions for loss of domain

\begin{tabular}{|c|c|c|c|c|c|}
\hline \multicolumn{2}{|l|}{ Round 1} & \multicolumn{2}{|l|}{ Round 2} & \multicolumn{2}{|l|}{ Round 3} \\
\hline Written definitions & & $\begin{array}{l}\text { Written definitions: panelists suggested } 1 \\
\text { alternatives* }\end{array}$ & nany & Written definitions: facilitator interventic & \\
\hline $\begin{array}{l}\text { 1. Chronic large } \\
\text { irreducible hernia }\end{array}$ & $0(0 \%)$ & 1. Hernia sac forms a second abdomen & $11(55 \%)$ & $\begin{array}{l}\text { A ventral hernia large enough such that } \\
\text { simple reduction in its contents and } \\
\text { primary fascial closure either cannot } \\
\text { be achieved without additional } \\
\text { reconstructive techniques or cannot } \\
\text { be achieved without significant risk } \\
\text { of complications due to the raised } \\
\text { intra-abdominal pressure }\end{array}$ & $20(100 \%)$ \\
\hline $\begin{array}{l}\text { 2. Hernia sac forms a } \\
\text { second abdomen }\end{array}$ & $7(35 \%)$ & $\begin{array}{l}\text { 2. Lateral retraction of the rectus } \\
\text { abdominis and the abdominal strap } \\
\text { muscles }\end{array}$ & $6(30 \%)$ & & \\
\hline $\begin{array}{l}\text { 3. Loss of the 'right } \\
\text { of domain' }\end{array}$ & $1(5 \%)$ & New suggested definitions & & & \\
\hline $\begin{array}{l}\text { 4. Lateral retraction } \\
\text { of the rectus } \\
\text { abdominis and the } \\
\text { abdominal strap } \\
\text { muscles }\end{array}$ & $9(45 \%)$ & $\begin{array}{l}\text { 3. A hernia where the fascia cannot be } \\
\text { approximated even with component } \\
\text { separation }\end{array}$ & $1(5 \%)$ & & \\
\hline \multirow[t]{6}{*}{ 5. Nil vote } & $3(15 \%)$ & $\begin{array}{l}\text { 4. Irreducible hernia due to lack of } \\
\text { space or volume }\end{array}$ & $6(30 \%)$ & & \\
\hline & & $\begin{array}{l}\text { 5. LOD is when the abdominal contents } \\
\text { protrude through a hernia defect and } \\
\text { is not able to be reduced and allow } \\
\text { for abdominal closure }\end{array}$ & $3(15 \%)$ & & \\
\hline & & $\begin{array}{l}\text { 6. Irreversible/reversible loss of } \\
\text { domain. Irreversible-the viscera } \\
\text { cannot be replaced into the } \\
\text { abdominal cavity by any technique. } \\
\text { Reversible loss of domain means the } \\
\text { ventral hernia can be reconstructed } \\
\text { using any technique }\end{array}$ & $5(25 \%)$ & & \\
\hline & & $\begin{array}{l}\text { 7. Loss of domain is when the abdomen } \\
\text { cannot be closed primarily without } \\
\text { the help of any augmentation } \\
\text { technique }\end{array}$ & $8(40 \%)$ & & \\
\hline & & $\begin{array}{l}\text { 8. A hernia where the fascia cannot be } \\
\text { approximated without developing } \\
\text { abdominal compartment syndrome }\end{array}$ & $3(15 \%)$ & & \\
\hline & & $\begin{array}{l}\text { 9. Closure of the fascia either is } \\
\text { impossible or can lead to high intra- } \\
\text { abdominal pressures, fascial } \\
\text { dehiscence or abdominal } \\
\text { compartment syndrome }\end{array}$ & $15(75 \%)$ & & \\
\hline \multicolumn{6}{|l|}{ Volumetric definitions } \\
\hline 1. Tanaka method & $8(40 \%)$ & 1. Tanaka method & $7(35 \%)$ & 1. Tanaka method & $2(10 \%)$ \\
\hline 2. Sabbagh method & $8(40 \%)$ & 2. Sabbagh method & $11(55 \%)$ & 2. Sabbagh method & $17(85 \%)$ \\
\hline 3. Nil vote & $4(20 \%)$ & 3. Nil vote & $2(10 \%)$ & 3. Nil vote & $1(5 \%)$ \\
\hline \multicolumn{6}{|l|}{ LOD cutoff point } \\
\hline 1. $15 \%$ & $1(5 \%)$ & 1. $20 \%$ & $5(25 \%)$ & 1. $20 \%$ & $4(20 \%)$ \\
\hline 2. $20 \%$ & $5(25 \%)$ & 2. Nil value & $15(75 \%)$ & 2. $30 \%$ & $1(5 \%)$ \\
\hline 3. $25 \%$ & $1(5 \%)$ & & & 3. Nil value & $15(75 \%)$ \\
\hline 4. $30 \%$ & $2(10 \%)$ & & & & $\begin{array}{l}\text { No } \\
\text { consensus }\end{array}$ \\
\hline $5.33 \%$ & $1(5 \%)$ & & & & \\
\hline
\end{tabular}


Table 1 continued

\begin{tabular}{lll}
\hline Round 1 & Round 2 & Round 3 \\
\hline $6.35 \%$ & $0(0 \%)$ & \\
$7.40 \%$ & $1(5 \%)$ & \\
$8.45 \%$ & $0(0 \%)$ & \\
$9.50 \%$ & $1(5 \%)$ & \\
10. Nil value & $8(40 \%)$ &
\end{tabular}

The panelist's thresholds for operative cutoff are also presented

$*$ Panelists allowed to select $\geq 1$ written definition

The written and volumetric definitions of LOD were taken from those identified by a recent systematic review [7]. Four written definitions and two volumetric definitions were identified. The Tanaka [14] and the Sabbagh [15] volumetric definitions were used. Before distribution to the panelists, the questionnaire was piloted on volunteers at the University College London Hospital. Recommendations were made regarding presentation and comprehension, and adjustments were made accordingly.

\section{Expert panel selection}

The panelists were selected by lead researchers MK, FM and ACJW. Selection was based on a combination of academic record and geographical location. In total, 20 experts were recruited; many were members of the American Hernia Society (AHS), British Hernia Society (BHS), European Hernia Society (EHS), German Hernia Society (DHS) and the Asian and Pacific Hernia Society (APHS). Panelists were asked to consent prior to voting. Consent involved maintenance of anonymity throughout voting rounds and commitment to completing the study, thereby avoiding panel attrition. Anonymity is central to Delphi methodology to avoid undue social pressures from dominant or dogmatic individuals and also affords participants opportunity to alter their opinion without losing face. Panelists were also asked to consent to taking part according to COPE criteria [16], thereby authenticating coauthorship and to declare any conflicts of interest (COIs) on the consent form. Those with COIs were asked to withdraw if they felt this influenced their voting.

While patient and public involvement (PPI) is sometimes incorporated into Delphi studies [17], we decided that PPI was not warranted here as the questions being asked required an understanding and interpretation of complex surgical concepts.

\section{Questionnaire distribution, data acquisition and analysis, and iteration}

After agreeing to participate, the consent form was emailed to panelists along with an outline of study aims and objectives. On receiving a signed consent form, the study protocol was emailed by return for approval.

The first round of voting was then administered by SGP and SH who did not vote, but acted as study facilitators. Data transfer occurred via electronic mail. MK, FM and ACJW did vote; while they had helped compile the list of panelists, they were blinded to co-panelist's responses during voting to maintain anonymity. SGP and SH predicted that three rounds of voting would be necessary before achieving consensus, but if this did not occur a teleconference between all panelists was planned (phase 6), a process known as the 'modified' Delphi technique [18]. Consensus was pre-defined as $80 \%$ of panelists selecting the term. If $<20 \%$ of the panelists selected a term, it was deleted from subsequent rounds. Anonymized responses were communicated to all panelists after each voting round via a table totaling the definitions selected and another detailing any extra definitions, comments and alterations suggested by panelists. These were added as possible options for subsequent rounds. Figures were presented as frequencies and percentages. We anticipated that establishing a written definition for LOD would be difficult as we believed previously published definitions were convoluted, counterintuitive and unlikely to reach consensus [7]. We recognized that it may be necessary to suggest new definitions in order to achieve consensus.

\section{Results}

All surgeons approached agreed to take part and consented. Six panelists were USA surgeons (MKL, GLA, CMD, $\mathrm{MTH}, \mathrm{BTH}$ and $\mathrm{KMFI}$ ), 6 were mainland European surgeons (FM, UAD, LNJ, AM, SMC and YR) and 5 were from the UK (ACdeB, DLS, NJS, JT and ACJW). The 
remaining were from South Africa (AB), South Korea (JPH) and Australia (NI). Voting started August 24, 2018, and completed January 24, 2019. All panelists completed the study.

\section{Round 1}

Table 1 shows results from each Delphi round. During Round 1, two of the written definitions ('chronic large irreducible hernia' and 'loss of the right of domain') were eliminated. In addition, panelists made 18 comments (Online supplement 2) and suggested an additional seven definitions, which were then presented in Round 2. Panelists were inconclusive regarding their preferred volumetric definition for LOD, with both Tanaka and Sabbagh each scoring $8(40 \%)$ votes. Four panelists abstained, citing a lack of evidence to support either method (e.g., 'need evidence to choose' and 'not sure either method is superior'). For their preferred LOD threshold/cut point, panelists indicated a range of values from 15 to $50 \%$. Five (25\%) panelists voted for a threshold of $20 \%$, two (10\%) for $30 \%$, and cut points $15 \%, 25 \%, 33 \%, 40 \%$ and $50 \%$ received one $(5 \%)$ vote each. Eight panelists chose 'nil value,' with accompanying feedback comments such as 'an absolute value is not relevant,' 'I adjust for clinical factors such as stiffness/thickness of lateral abdominal musculature, COPD. etc.' and 'LOD is clinically significant simply because it exists.' Only '20\%' and 'nil value' scored $\geq 20 \%$ of the votes, so only these two options were presented in Round 2.

\section{Round 2}

Nine written definitions were presented in Round 2, including the additional 7 definitions suggested by panelists during round one. Thematic analysis of the proposed definitions by SGP and SH revealed three common themes/concepts: (1) large hernias with LOD are irreducible due to inadequate space inside the abdominal cavity; (2) primary fascial closure cannot be achieved without surgical augmentation; and (3) primary fascial closure would cause compartment syndrome (Table 2). To determine which of these themes/concepts were most relevant, panelists were asked to select any definition they agreed with during Round 2, i.e., multiple selections were possible. To demonstrate the difference between the two volumetric methods, Tanaka and Sabbagh, a new schematic diagram was drawn for Round 2 (Fig. 1b).

Panelists agreed with several suggested written definitions (Table 1). The two literature definitions 'hernia sac forms a second abdomen' and the physiological definition 'lateral retraction of the recti muscles' received $11(55 \%)$ and $6(30 \%)$ votes, respectively. The number of votes for the remaining 7 definitions ranged from $1(5 \%)$ to 15 $(75 \%)$. All three concepts presented in the definitions proposed by panelists were selected repeatedly (Online supplement 3 and Table 2); 'irreducibility due to lack of space' was selected by 15 (75\%); 'no primary closure without using an augmentation technique' was selected by 13 (65\%); and 'primary closure leading to compartment syndrome' was selected by 18 (90\%) (Table 2). Regarding their preferred volumetric definition, panelists chose Sabbagh over Tanaka: $11(55 \%)$ versus 7 (35\%) with two abstentions. Twenty percent was chosen as a clinical cut point by $5(25 \%)$ panelists. Fifteen $(75 \%)$ panelists selected 'nil value.'

\section{Round 3}

Because the three themes/concepts proposed in Round 2 were popular, SGP and SH designed a definition incorporating all three themes/concepts, proposing the following definition for Round 3:

A ventral hernia large enough such that simple reduction in its contents and primary fascial closure either cannot be achieved without additional reconstructive techniques or cannot be achieved without

Table 2 Combining the three concepts to design a new definition for loss of domain

\begin{tabular}{ll}
\hline Concepts & $\begin{array}{l}\text { Round } 2 \\
(\%)\end{array}$ \\
\hline $\begin{array}{l}\text { 1. Irreducible due to lack of space } \\
\text { 2. Primary fascial closure cannot be achieved without using an augmentation technique. }\end{array}$ & $\begin{array}{l}15 \%) \\
(65 \%) \\
\text { 3. Primary closure would lead to compartment syndrome. }\end{array}$ \\
\hline $\begin{array}{l}\text { Definition designed by the facilitators } \\
18 \%)\end{array}$ & Round 3 \\
\hline $\begin{array}{l}\text { A ventral hernia large enough such that simple reduction in its contents and primary fascial closure either cannot be achieved } \\
\text { without additional reconstructive techniques or cannot be achieved without significant risk of complications due to the raised }\end{array}$ & $200 \%)$ \\
\hline intra-abdominal pressure.
\end{tabular}


significant risk of complications due to the raised intra-abdominal pressure.

They viewed the definitions, 'hernia sac forming a second abdomen' and 'lateral retraction of the recti muscles' as both lacking precision, since all ventral hernias involve these to some extent. These two definitions were therefore removed from Round 3 with the approval of MKL, FM and ACJW.

During Round 3, the proposed written definition achieved complete consensus, attracting 20 (100\%) votes. Regarding the volumetric definition, the Sabbagh method received 17 (85\%) votes, thereby also achieving consensus. However, panelists remained undecided regarding the clinical threshold value with 'nil value' receiving $15(75 \%)$ votes, $20 \% 4(20 \%)$ votes, and one panelist (5\%) again suggested a cut point of $30 \%$. Consensus on this point was therefore not achieved.

\section{Discussion}

Neither a standardized written or volumetric definition exists for LOD. This limits the utility of LOD as a morphological descriptor and as an outcomes predictor. Using Delphi methodology, a panel of internationally recognized experts in abdominal wall reconstruction have agreed on standardized written and volumetric definitions for LOD. As the subspecialty of abdominal wall reconstruction continues to expand, these standardized definitions for LOD will hopefully reduce clinical inconsistency and facilitate research activity.

For 20 years, hernia academics have been calling for a 'common language' to describe and define ventral hernia [19]. In 2000, Schumpelick proposed his incisional hernia classification scale [20], followed shortly by the betterknown classification system from Chevrel and Rath [21]. Many alternatives have been published subsequently [22-30], but few have been externally validated and, if so, with limited success [31-33]. Clinical utility has suffered as a result. Importantly, none of these scales include a welldefined volumetric concept for LOD. Evidence suggests that wider hernias [34, 35] and hernias with increasing defect surface area [8] have the worst post-repair outcomes and highest recurrence rates. Generally, hernia surgeons believe that large hernias with significant LOD are the most complex to repair and suffer the worst postoperative outcomes. Consequently, generally accepted written and volumetric definitions are required to standardize morphological description and volume measurements so that the role of LOD as a prognostic factor can be investigated. Future ventral hernia grading scales may incorporate LOD.
The written definition of LOD was created after thematic analysis of panelist feedback. By analyzing the proposed written definitions, we identified three common themes: irreducibility due to lack of intra-abdominal space; use of reconstructive techniques to facilitate reduction; and an increased risk of complications due to the raised intraabdominal pressure. These were combined into a single definition that then achieved $100 \%$ consensus. This definition attempts to characterize those hernias whose repair is likely to be challenging which therefore require specific expertise in abdominal wall surgery. The definition is explicit that additional reconstructive techniques are likely because primary fascial closure alone would precipitate potentially serious complications due to the abruptly increased intra-abdominal pressure.

Initially panelists were undecided as to their preferred volumetric method, with Tanaka [14] and Sabbagh [15] both receiving equal votes in Round 1. Eventually, consensus settled on the Sabbagh method and panelists confirmed this in their private correspondence with the facilitators. For example, 'Sabbagh seems much easier than Tanaka for clinical use,' and 'the Tanaka method is confusing and conceptually difficult. Much like relative risk is much easier to understand compared to odds ratios, Sabbagh is much easier to understand compared to Tanaka.' These comments support the feasibility of using the Sabbagh method in a clinical setting. Indeed, a straw poll of the audience at 'Abdominal Wall Reconstruction Europe 2019' (London, UK) by one of the authors found that Sabbagh was preferred by a large majority. Furthermore, LOD is often reported as a percentage. When using Tanaka, the value will surpass 100 when more than $50 \%$ of the abdomino-pelvic volume lies outside the abdominal cavity. In contrast, Sabbagh is always less than 100, making it conceptually easier. This likely contributed to achieving consensus in its favor.

We were unable to establish consensus regarding a LOD threshold above which panelists would consider not operating. Most panelists, 15 (75\%), selected 'nil value' stating that their decision whether to or not to operate was multifaceted, incorporating comorbidities and not based on hernia size in isolation. However, $5(25 \%)$ panelists did select threshold values in Round 3. Indeed, one panelist who voted consistently for $20 \%$ proposed a written definition that separated ventral hernias into two categories: those with reversible LOD and those with irreversible LOD, i.e., those with large ventral hernias that can be repaired and those that cannot. The concept that LOD may be irreversible in some patients is interesting. Despite considerable morbidity (abdominal pain, back pain, respiratory dysfunction), patients with giant ventral hernias are often denied surgery because the surgeon believes they cannot return the abdominal viscera to the abdomino-pelvic 
cavity safely. There is little existing evidence to support this opinion beyond surgical experience. So, during this study, we were in effect asking panelists to declare their own threshold for discriminating between reversible and irreversible LOD. As consensus was not established, this value remains unknown. Further work is required around which factors impact on the decision to operate and, in particular, whether a LOD threshold predicts postoperative failure.

Our study does have limitations. As anticipated, the facilitators' role was relatively active and required thematic analysis of proposed definitions to create a new written definition in order to achieve consensus. Two written definitions were removed as they were deemed at variance with the definitions proposed by panelists. Facilitator intervention is sometimes necessary to achieve consensus and was judged acceptable in our study since the written definition proposed ultimately was approved by all panelists. It is possible that restricting panelists to expert abdominal wall surgeons may have introduced bias that could have resulted in an overly complex written definition for LOD. It also could have resulted in an overly high LOD threshold value, if consensus had been reached, since this group will likely be more willing to tackle complex cases. However, we would argue that expert surgeons are the most appropriate 'consumers' for these definitions once accepted since complex abdominal wall reconstruction is not a problem that should be tackled by general surgeons.

Furthermore, our chosen group of panelists mainly represent countries from the developed world, meaning that within our group there was no representation from Northern Africa, the Middle East or the Indian subcontinent. Typical patient profiles in these regions differ, with lower rates of obesity [36] and sarcopenia [37], and higher rates of manual labor, trauma, late presentation and emergency presentation of disease [38]. This is likely to affect hernia etiology with higher rates of primary and traumatic ventral hernia and lower rates of incisional hernia. Materials and techniques used to repair ventral hernias may also differ due to a lack of healthcare resources. Despite this, we believe the definitions proposed by this study are straightforward and easily applicable to all human populations and profiles. Indeed, even in developed countries there is a spectrum of patients that present to the outpatient clinic and all co-authors believe these definitions can be applied unreservedly.

This study arose following a systemic review that called for standardized written and volumetric definitions for LOD [7]. Generally accepted international definitions will avoid confusion and enhance both clinical reporting and research reporting. We also recognize that definitions are not static and must adapt to new knowledge. The authors hope the definitions proposed in this work are endorsed by surgeons and international hernia societies.

Funding This work was funded by the UK National Institute for Health Research (NIHR) (grant RfPB PB-PG-0816-20005) and Allergan (Dublin, Ireland). Neither funder was involved in the planning, methodology, analysis or write-up of the research. The views and opinions expressed by authors in this publication are those of the authors and do not necessarily reflect those of the National Health Service, NIHR or Department of Health. SH was also supported by the NIHR University College London Hospitals Biomedical Research Centre.

\section{Compliance with ethical standards}

Conflict of interest Windsor ACJ declares conflicts of interest not directly related to the submitted work; consultant advisor for TELA $\mathrm{BIO}$; and educational grants and speaker for: BARD, LifeCell and Cook. Boutall A. declares conflicts of interest not related to the submitted work; travel grants from Ethicon, Bard and Medtronic; and consultancy work for Medtronic. De Beaux A. declares conflicts of interest not directly related to the submitted work; speaker for BD Bard and Medtronic; and trainer for Bard BD. Heniford BT declares conflicts of interest not directly related to the submitted work and consultancy work for WL Gore, Stryker Corporation and Allergan Plc. Jorgensen LN declares conflicts of interest not directly related to the submitted work and educational grants from Bard BD and Medtronic. Montgomery A. declares conflicts of interest not directly related to the submitted work and speaker for Bard BD. MoralesConde S declares conflicts of interest not directly related to the submitted work; speaker for Bard BD; educational work for Medtronic, Ethicon, Storz Medical, Olympus, Stryker Corporation and WL Gore; and consultancy work for Dipro Medical. Muysoms F declares conflicts of interest not directly related to the submitted work; consultancy work for Medtronic, Intuitive Surgical, CMR surgical and Dynamesh; educational grants from Medtronic and Dynamesh; and speaker for Bard BD. Renard Y. declares conflicts of interest not directly related to the submitted work and educational grants from Bard BD, Hartmann. Sanders DL declares conflicts of interest not directly related to the submitted work; educational grant, speakers fee and fee for post-market surveillance from Medtronic; and speakers fee and consultant for Bard BD. Smart NJ declares conflicts of interest not directly related to the submitted work and educational and speaker grants from WL Gore and Medtronic. Torkington $\mathrm{J}$ declares conflicts of interest not directly related to the submitted work and speaker and consultant for Medtronic. Parker SG, Halligan S, Adrales GL, Deitz UA, Divino CM, Hawn MT, Hong JP, Ibrahim N, Itani KMF and Liang MK declare no conflict of interest.

Ethical approval Ethical permission is not required by our institution for Delphi studies.

Human and animal rights This article does not contain any studies with human participants performed by any of the authors.

Informed consent This article does not include patients, and therefore, informed consent was not applicable.

Open Access This article is licensed under a Creative Commons Attribution 4.0 International License, which permits use, sharing, adaptation, distribution and reproduction in any medium or format, as long as you give appropriate credit to the original author(s) and the 
source, provide a link to the Creative Commons licence, and indicate if changes were made. The images or other third party material in this article are included in the article's Creative Commons licence, unless indicated otherwise in a credit line to the material. If material is not included in the article's Creative Commons licence and your intended use is not permitted by statutory regulation or exceeds the permitted use, you will need to obtain permission directly from the copyright holder. To view a copy of this licence, visit http://creativecommons. org/licenses/by/4.0/.

\section{References}

1. Shelton J, Poulose BK, Phillips S et al (2012) Epidemiology and cost of ventral hernia repair: making the case for hernia research. Hernia 16:179-183

2. Hospital Episode Statistics (2017) UK ventral hernia data: Report on request

3. Lutz W, Sanderson W, Scherbov S (2008) The coming acceleration of global population ageing. Nature 451:716-719

4. The Royal College of Physicians (2004) Storing up problems: the medical case for a slimmer nation

5. Soop M, Carlson GL (2017) Recent developments in the surgical management of complex intra-abdominal infection. Br J Surg 104(2):e65-e74

6. Watson MJ, Kundu N, Coppa C et al (2013) Role of tissue expanders in patients with loss of abdominal domain awaiting intestinal transplantation. Transpl Int 26(12):1184-1190

7. Parker SG, Halligan S, Blackburn S et al (2019) What exactly is meant by 'loss of domain' for ventral hernia repair? Systematic review of definitions. World J Surg 43(2):396-404. https://doi. org/10.1007/s00268-018-4783-7

8. Poruk KE, Farrow N, Azar F et al (2016) Effect of hernia size on operative repair and post-operative outcomes after open ventral hernia repair. Hernia 20(6):805-810

9. Fiore JF, Bialocerkowski A, Browning L et al (2012) Criteria to determine readiness for hospital discharge following colorectal surgery: an international consensus using the delphi technique. Dis Colon Rectum 55(4):416-423

10. Rowe G, Wright G (1999) The delphi technique as a forecasting tool: issues and analysis. Int $\mathrm{J}$ Forecast 15:353-375

11. Boulkedid R, Abdoul H, Loustau M et al (2011) Using and reporting the delphi method for selecting healthcare quality indicators: a systematic review. PLoS ONE 6(6):e20476

12. Jorm A (2015) Using the delphi expert consensus method in mental health research. ANZJP 49(10):887-897

13. Mull HJ, Graham LA, Morris MS et al (2018) Association of postoperative readmissions with surgical quality using a delphi consensus process to identify relevant diagnosis codes. JAMA Surg 153(8):728-737

14. Tanaka EY, Yoo JH, Rodrigues AJ Jr et al (2010) A computerized tomography scan method for calculating the hernia sac and abdominal cavity volume in complex large incisional hernia with loss of domain. Hernia 14:63-69

15. Sabbagh C, Dumont F, Robert B et al (2011) Peritoneal volume is predictive of tension-free fascia closure of large incisional hernias with loss of domain: a prospective study. Hernia 15:559-565

16. COPE Council. What constitutes authorship? COPE Discussion Document. 9 June 2014. https://publicationethics.org/files/ Authorship_DiscussionDocument.pdf. Accessed May 28, 2018

17. Tierman J, Cook A, Geh I et al (2014) Use of a modified Delphi approach to develop research priorities for the association of coloproctology of Great Britain and Ireland. Colorectal Dis 16:965-970
18. Schneider P, Evaniew N, Rendon JS et al (2016) Moving forward through consensus: protocol for a modified Delphi approach to determine the top research priorities in the field of orthopaedic oncology. BMJ Open 6(5):e011780

19. Schumpelick V, Kingsnorth AN (1999) Panel discussions: classification. In: Schumpelick V, Kingsnorth AN (eds) Incisional Hernia. Springer, Berlin, pp 491-492

20. Narbenhernie Schumpelick V (2000) In: Schumpelick V (ed) Hernien. Thieme Publishing p, Stuttgart, pp 266-269

21. Chevrel JP, Rath AM (2000) Classification of incisional hernias of the abdominal wall. Hernia 4(1):7-11

22. Korenkov M, Paul A, Sauerland S et al (2001) Classification and surgical treatment of incisional hernia; results of an expert meeting. Langenbecks Arch Surg 386(1):65-73

23. Dietz UA, Hamelmann W, Winkler MS et al (2007) An alternative classification of incisional hernias enlisting morphology, body type and risk factors in the assessment of prognosis and tailoring of surgical technique. JPRAS 60:383-388

24. Muysoms FE, Miserez M, Berrevoet F et al (2009) Classification of primary and incisional abdominal wall hernias. Hernia 13(4):407-414

25. Breuing K, Butler CE, Ferzoco S et al (2000) Incisional ventral hernias: review of the literature and recommendations regarding the grading and technique of repair. Surgery 148(3):544-558

26. Kanters AE, Krpata DM, Blatnik JA et al (2012) Modified hernia grading scale to stratify surgical site occurrence after open ventral hernia repairs. J Am Coll Surg 215(6):787-793

27. Petro CC, Rourke CPO, Criss CN et al (2016) Designing a ventral hernia staging system. Hernia 20:111-117

28. Slater NJ, Montgomery A, Berrevoet F et al (2014) Criteria for definition of a complex abdominal wall hernia. Hernia 18:7-17

29. Poruk KE, Hicks CW, Trent Magruder J et al (2017) Creation of a novel risk score for surgical site infection and occurrence after ventral hernia repair. Hernia 21(2):261-269

30. Berger RL, Li LT, Hicks SC et al (2013) Development and validation of a risk-stratification score for surgical site occurrence and surgical site infection after open ventral hernia repair. J Am Coll Surg 217(6):974-982

31. Mitchell TO, Holihan JL, Askenasy EP et al (2016) Do risk calculators accurately predict surgical site occurrences? J Surg Res 203(1):56-63

32. Liang MK, Goodenough CJ, Martindale RG et al (2015) External validation of the ventral hernia risk score for prediction of surgical site infections. Surg Infect 16(1):36-40

33. Baucom RB, Ousley J, Oyefule OO et al (2015) Incisional hernia classification predicts wound complications two years after repair. Am Surg 81(7):679-686

34. Helgstrand F, Rosenberg J, Kehlet H et al (2013) Nationwide prospective study of outcomes after elective incisional hernia repair. J Am Coll Surg 216(2):217-228

35. Vidovic D, Jurisic D, Franjic B et al (2006) Factors affecting recurrence after incisional hernia repair. Hernia 10(4):322-325

36. NCD Risk Factor Collaboration (2017) Worldwide trends in body-mass index, underweight, overweight, and obesity from 1975 to 2016: a pooled analysis of 2416 population-based measurement studies in 128.9 million children, adolescents, and adults. Lancet 390:2627-2642

37. Shafiee G, Keshtkar A, Soltani A et al (2017) Prevalence of sarcopenia in the world: a systematic review and meta- analysis of general population studies. J Diabetes Metab Disord 16:21

38. Gyedu A, Stewart B, Wadie R et al (2019) Population-based rates of hernia surgery in Ghana. Hernia Aug. 1-7

Publisher's Note Springer Nature remains neutral with regard to jurisdictional claims in published maps and institutional affiliations. 